\title{
Coalesced Quality Management System
}

\author{
A Collaborative Service Delivery Model
}

\author{
A. Pathanjali Sastri \\ Lecturer, Department of Computer Application, \\ V.R.Siddhartha Engineering College, \\ Kanuru Vijayawada - 520 007, Andhra Pradesh, India. \\ akellapatanjali@yahoo.com
}

\begin{abstract}
Developing software in a stipulated time frame and within a budget is not good enough if the product developed is full of bugs and today end users are demanding higher quality software than ever before. Project lifecycle starts with preProject work all the way through to post-Project. Projects need to be set up correctly from the beginning to ensure success. As the software market matures, users want to be assured of quality. In order to check such unpleasant incidents or potential problems lurking around the corner for software development teams, we need a quality framework, that not only to assess the common challenges that are likely to come in the way while executing the projects but also to focus on winning the deal during proposal stage.

Our research paper is an honest appraisal of the reasons behind the failure of projects and an attempt to address valuable pointers for the successes of future projects. "Coalesced Quality Management Framework (CQMF)" is a theoretical model to bring the best of Quality to the work products developed and to gain the firsthand knowledge of all the projects, defects, and quality metrics and report to the Management so that missed deadlines and enhancement of budget are avoided providing an opportunity to deliver the end product to the satisfaction of the customer. With this framework the project stakeholders and the management constantly validate what is built and verify how it is being built.
\end{abstract}

Keywords- Quality Assurance, Operational Excellence, Coalesced Quality Management System, Business Analyst, phase gate reviews

\section{INTRODUCTION}

There are many studies attempting to quantify the cost of software failures. They don't agree on percentages but they generally agree that the number is at least 50 to 80 billion dollar range annually [1]. Implementing a complex new product may be the most difficult and risky effort an organization is facing today. An experienced project manager is identified for a heavy budget project and is made responsible for delivering on the contractual commitments. But they have to deliver a solution that meets customer's objectives and for this, the project team should have experience and capability to ensure that the project will succeed. If the staff has limited experience in the required technologies, methodologies and in management, failure is not an option. Poor quality management

\author{
K. Nageswara Rao \\ Professor \& Head, Department of Computer Science and \\ Engineering, \\ P.V.P.Siddhartha Institute of Technology, \\ Kanuru, Vijayawada - 520 007, Andhra Pradesh, India \\ drknrao@ieee.org
}

can lead to rework, customer dissatisfaction, higher costs, and missed deadlines. There is a need to apply an effective framework that must be prudently applied in order to identify, anticipate and address these risks before they cripple the project. With all that we have on the line, there must be always an unbiased advice on the potential risks to the project and to the organization. The organizations need an effective governance to standardize on a framework comprising process, tools, and resources (experts) that would help them save time and reduce product/process failures in order to bring in the results that may likely be in the best interests of the organization.

This paper proposes a CQMF model that recommends that by implementing CQMS model and adapting effective people practices i.e. involving appropriate stakeholders in each stage of the life cycle, a project will definitely be executed towards the success. For such, the paper is organized as follows. Section II briefly surveys the reasons for failure of projects; Section III describes the existing quality processes in organizations; Section IV discusses the limitations of the present quality structures in organizations; Section V describes about the importance of effective people practices; and Sections VI, VII, VII, and IX describe the proposed approaches.

\section{A SURVEY OF REASONS FOR FAILURE OF PROJECTS}

Our research work started with good amount of literature survey through Internet and journal articles on project failure [1][4][10][11][14]. Besides, some informal interviews were also conducted with few program managers and project managers working in top notch companies. Data were collected by interviewing project managers and consultants using a semistructured interview schedule. The errors are not actual code defects but are considered to be the errors or failures of governance, committed by a governing body like a steering committee, errors and failures of project management and errors and failures of software engineering. The samples of seven large IT projects were examined from four perspectives: Governance, Business case, Organizational capacity, and Project management as shown in table 1 . 
TABLE 1 ANALYSIS OF FAILURES TO DETERMINE ROOT CAUSES OF POOR OUTCOME

\begin{tabular}{|c|c|c|c|}
\hline S.No & Parameter & Explanation of the issues & $\begin{array}{l}\text { No. of projects (Out } \\
\text { of seven projects) }\end{array}$ \\
\hline 1 & Governance & $\begin{array}{l}\text { 1. Varied widely from project to project } \\
\text { 2. Governance responsibilities were not carried out adequately because the processes used to } \\
\text { approve and manage large IT projects did not increase the project's likelihood of success. } \\
\text { 3. All the projects experienced lack of scrutiny at project conception and initiation, and was } \\
\text { eventually proven to be fundamentally unwise. }\end{array}$ & Seven \\
\hline 2 & Business Case & $\begin{array}{l}\text { Projects looked at were allowed to proceed with a business case that was incomplete and the } \\
\text { projects and the steering team did not clearly define the business needs it expected the project } \\
\text { to meet. }\end{array}$ & Six \\
\hline 3 & $\begin{array}{l}\text { Organizational } \\
\text { capacity }\end{array}$ & $\begin{array}{c}\text { Projects undertaken lacked the appropriate skills and experience to manage the large IT } \\
\text { projects. }\end{array}$ & Five \\
\hline 4 & $\begin{array}{c}\text { Project } \\
\text { Management }\end{array}$ & $\begin{array}{l}\text { 1. Quality of project management ranged from good to poor but in two cases, poor project } \\
\text { management led to long delays and large cost overruns. } \\
\text { 2. The PM did not follow accepted best practices in managing the project. }\end{array}$ & Five \\
\hline
\end{tabular}

Worth noting is that most organizations that experienced the software failures have not attempted to study the root causes of the failures. Unfortunately, most organizations don't see preventing failure as an urgent matter, even though that view risks harming and maybe even destroying the organization [5]. Understanding why this attitude persists is not just an academic exercise; it has tremendous implications for business and society [9]. The ways in which an organization develops software can be viewed as a system within which the organization prevents defects in it, output through different methods of prevention, detection and removal. Figure 1 depicts a defect prevention model for any organization.

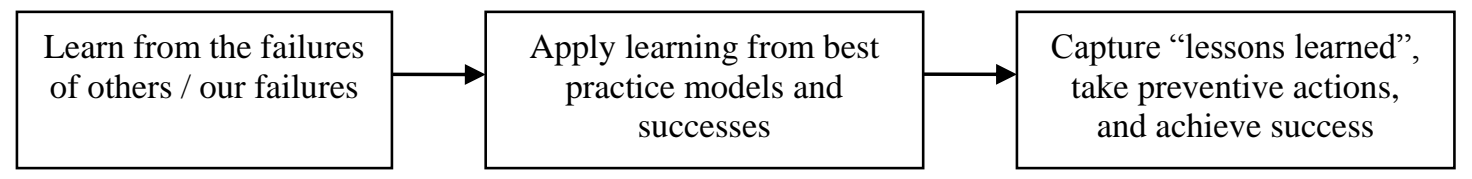

Figure 1 Defect Prevention Model

\section{EXISTING QuAlity Assurance Process}

Software Quality Assurance is the planned and systematic set of activities that ensures that software life cycle processes and products conform to requirements, standards, and procedures [IEEE 610.12]. Full life cycle Software Assurance activities provide independent and objective assessments of the processes and quality of the product. Figure 2 shows the activities performed by quality group throughout project life cycle. The Quality Management System (QMS) consists of detailed checklists, standards, templates and guidelines exist within the processes to bring in rigor and predictability into every aspect of project planning and execution. These processes and templates are maintained in a centralized repository and are made available across various types of projects (testing, conversion, maintenance, development, package implementation, etc) within the organization which are used in every aspect of the project (requirements analysis, design, change/ configuration management, tailoring, defect or schedule estimation, etc). Software Quality Assurance (SQA) team maintains and enhances the Quality Management System repository and Knowledge Database, based on the experiences gained from the project implementation and bench marking against international practices. The knowledge database consists of project metrics database, process metrics database and a process-capability baseline. Project leaders use these to estimate effort, schedule tasks and predict defect levels during the project-planning phase. The process database is based on data from past projects and ensures that project plans are realistic. Further, project monitoring based on these metrics increases its effectiveness. The role of SQA team is to create the process-oriented mind-set within the organization and always stick to its commitment and help/facilitate projects to consistently deliver quality software solutions on time by conforming to existing quality standards and monitoring the work products for conformance to standards and processes.

\section{Limitations With ThE PRESENT Quality MANAGEMENT STRUCTURE}

Quality Assurance activity will be considered as a no valueadded function if it does not focus on opportunities for early error detection, problem prevention, and risk identification and mitigation and earlier detection and identification yields fewer costs to fix and less schedule impact. By adhering to comprehensive quality management system and quality assurance processes, it could be possible to leverage project 
experiences and learning to bring about predictability in processes and continuity \& sustainability in quality if this system is controlled and run by the right people. Most of the times the SQA/SQC activities end up in corrective action by analyzing the origin of the defects, examining the SDLC to determine where the defect was introduced (Requirements or Design or Coding) and reviewing these with the project managers and other associates for possible improvements. This type of approach will not work for large projects or critical projects.

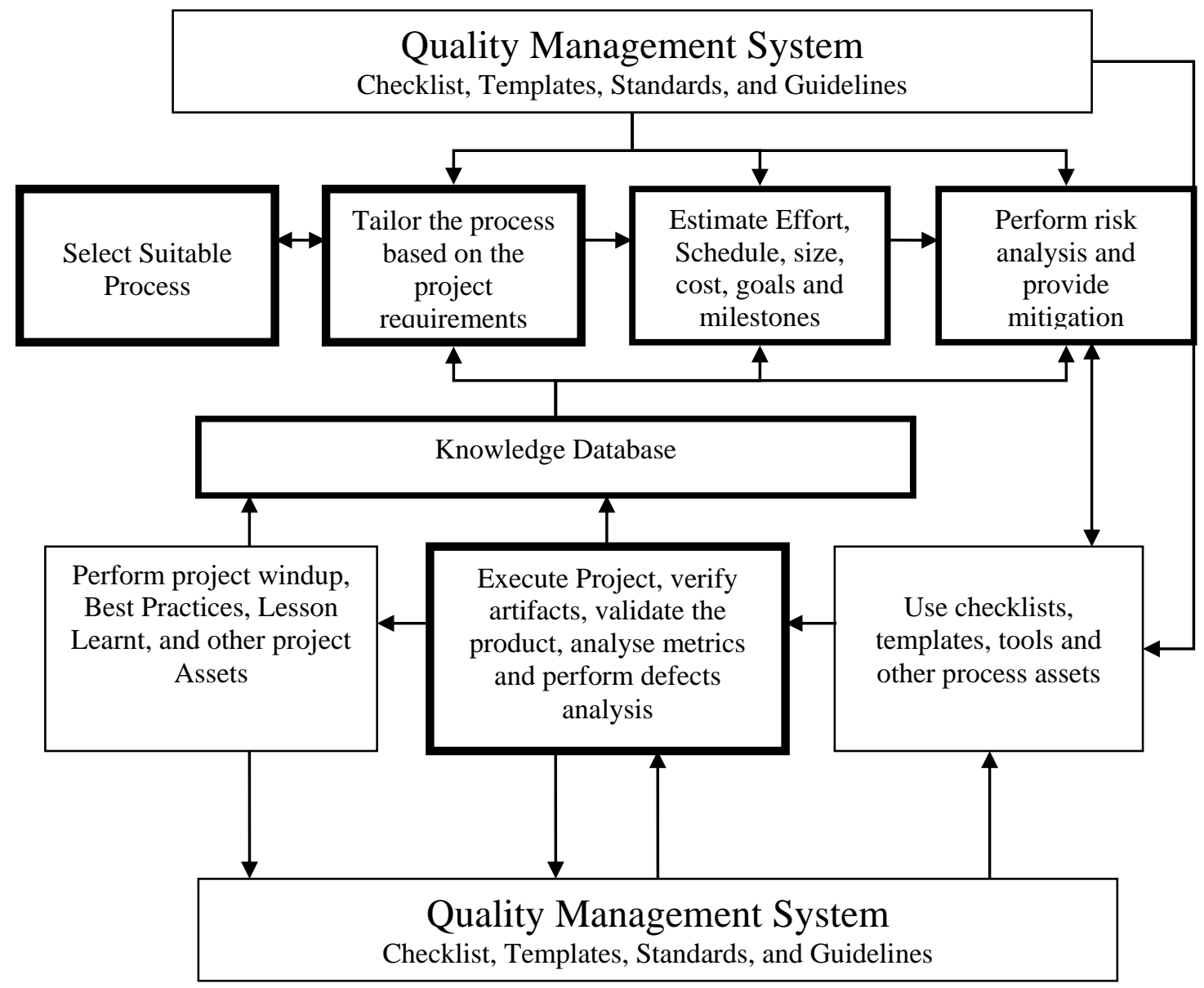

Figure 2 Typical QMS and performed activities by the system

Suitable development processes have a considerable influence or im improving software quality and models such as ISO or CMMI have been deployed for a long time for improving development processes. But it seems that these efforts remain almost fruitless when we look into the reasons of failure of projects. However, it must also be noted that, good processes may well ensure better products, but good processes alone are by far no guarantee for perfect products. It is thus absolutely essential to take the time to work on a suitable development process in an iterative way together with those involved and accompanied by experienced people.

\section{OPERATIONAL EXCELLENCE THROUGH EFFECTIVE PEOPLE PRACTICES}

Figure 3 shows the success of achieving the goals largely depends on the people in the organization and key to constant focus on operational excellence emerges from the assignment of right set of people with required competencies [8].

Quality Result $=$ Functional Quality + Quality of Reliability + Quality of Cost + Quality of Delivery Schedule

\begin{tabular}{|c|c|c|}
\hline $\begin{array}{l}\text { Quality } \\
\text { Results }\end{array}$ & & $\begin{array}{c}\text { Quality People + Conglomeration of highly effective and efficient } \\
\text { workforce practices + Tools }\end{array}$ \\
\cline { 2 - 4 }
\end{tabular}

Figure 3 Framework to drive operational excellence 


\section{CoAlesced Quality MANagement SYSTEM (CQMS) - A Collaborative Service Delivery Model}

Many systems were developed with functionality in mind rather than with operations or usability in mind. According to the man who invented management, Peter F. Drucker, "Efficiency is doing things right, Effectiveness is doing right things". The proposed framework shown in figure 4 is a Coalesced Quality Management System (CQMS) that defines a Collaborative Service Delivery Model and serves as organisation's "eyes and ears" into the inner workings of the project which is independent of the project team and the customer. It provide insight into all aspects of the project: requirements management, adherence to the schedule and budget, project governance, technical architectures and change management with the involvement of IV\&V pool, subject matter expects, groups like portfolio management office, quality group, and process/product/tool repository.

The model shown in figure 4 will address the issues shown in table 1, with earlier detection \& Prevention of errors either in the product or in process thus bringing down the total cost of quality. This model assures that reviews are conducted by experienced, qualified, and dispassionate experts and projects are on track before proceeding to the next gate as shown in the figure 5. Viewing defects in released product is not the desired one and there should be defenses in depth to prevent defects. So the activities of QMS shown as dark boxes in figure 2 need to be performed and assessed by the people from expert pool (shown as a dark box in figure 4).

\section{JUSTIFICATION OF THE CQMS MODEL}

According to new research, success in 68 percent of technology projects is "improbable". Poor requirements analysis causes many of these failures, meaning projects are doomed right from the start [2]. In many organizations, requirements are not detailed enough to enable project to make needed changes and get to the end goal reliably. Key to the success of the design and development of a software system like bio-informatics software or an e-security solution mostly depends on the obtaining requirements from different people with expertise in different competencies. E.g., developing bioinformatics software requires the services of a Biology and/or bio-chemistry expert to provide domain related requirements and test the software, a mathematician to provide guidance towards optimal algorithms, few computer scientists to develop the code etc. Using this model we intend to reduce the number of iterations in the process of creating the final product by involving expert pool in conception, initiation, requirements, design and testing phases of the life-cycle.

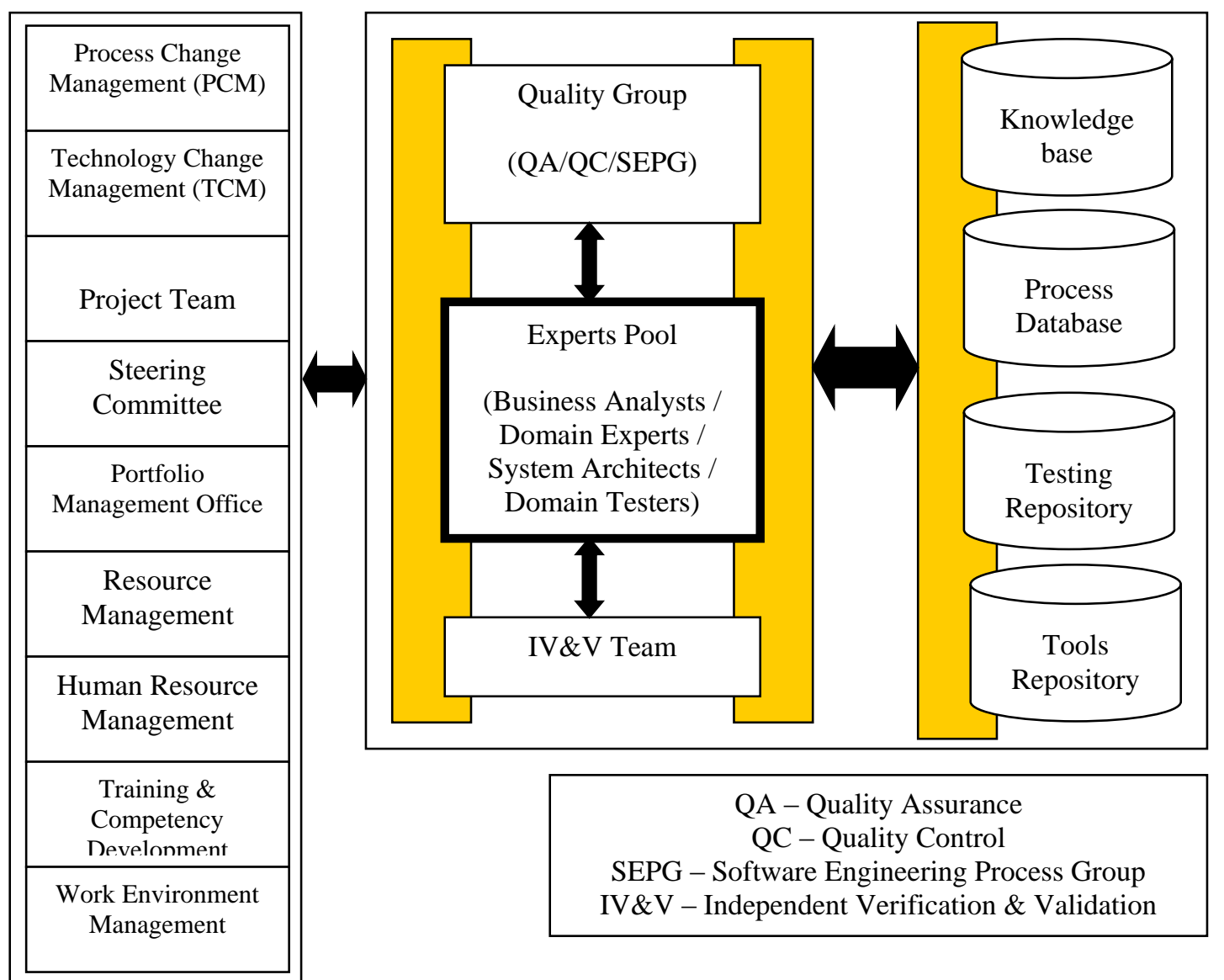

Figure 4 Coalesced Quality Management System (CQMS) 
As the operational excellence is defined as a goal of executing projects in a manner that improves timely delivery and quality of deliverables while reducing the rework, the CQMS addresses the problems like the project conception that results in unwise approaches because of (a) inadequate analyses of business issues because the participants lack the necessary qualifications or experience and (b) ineffective review programs performed in unsupportive project environments (barriers to success of the projects) that contribute more towards the failure of the large projects by primarily focusing on the customer needs and optimization of people, assets, and processes.

\section{InVOLVEMENT OF EXPERTS DURING PROPOSAL STAGE, REQUiREMENTS AND TESTING PHASES}

It has been observed industry wide that in many cases, the root cause of high cost and schedule overruns and poor quality of the deliverables lie in the proposal stage [7]. Also the projects surveyed seem to be not utilizing sufficient business analysis skill to consistently bring projects in on time and budget [6]. New study from IAG consulting finds companies with poor requirements spend on average $\$ 2.24 \mathrm{~m}$ more per project [14]. Many project teams contain domain generalists who learn just enough domain information required for the project or sometimes developers are moved to business analysis role and this would prevent them from working based on anticipation. By understanding the business we don't mean having an in-depth knowledge of how business operates and the projects need to involve a deep domain expert/Business Analyst to perform business process analysis, requirements specification and outline design, acceptance testing and system implementation work. With inadequate, inappropriate or inaccurate requirements as a major contributor to project overruns and failure, the role of a skilled Business Analyst in a project team has become more critical than ever [3].

The expected skill set of Business Analyst [9]:
Hard Skills:
(a) Requirements Elicitation
(Investigate, Analyse, and Specify)
(b) Business Systems Modeling (Process, Data, and Business rules)
Soft Skills: Analysis, Creative thinking, Interviewing, Presentation and Negotiation.

Curve 1 in figure 5 shows the underestimation of the complexity of the project with inadequate, inappropriate or inaccurate requirements which end up in project overruns and failure. Since a broad experience of business is required during the conception, initiation, requirements and testing phases, the involvement of professional business analyst is more critical than ever during these phases. Curve 2 in figure 5 depicts the decreasing complexity of the project with the involvement of business analyst which compromises on the three major elements on-time delivery, within cost budget and quality of product. The focus of the CQMS is to identify defects as early as possible, when they are easier and more cost effective to correct. This plan provides a framework of activities that are performed within phases of the project life cycle (figure 5).

The key practices help significantly in this regard are:

(i) Involvement of Experts (Business Analysts / Domain Experts or Subject Matter Experts) during proposal stage and requirements phase.

(ii) Involvement of Experts (Business Analysts / Domain Experts or Subject Matter Experts / System Architects) during design phase.

(iii) Involvement of Experts (Business Analysts / Domain Experts or Subject Matter Experts / Domain Testers) during testing phase.

\section{INVOLVEMENT OF EXPERTS IN INDEPENDENT Verification Validation (IVV) TEAm to Conduct Phase GATE REVIEWS}

As observed from the failure projects from the literature survey, the organizations struggle to implement an effective review program. The survey analysis[12][13] also shows that there is no visible and sustained commitment to reviews from project manager or quality manager in most of the projects (management problem) and it was also found that holding reviews would be too unpleasant in an environment which is not supportive of quality practices. But we see project managers want to deliver quality products and at the same time they also feel pressure to release products quickly and turn resistance towards inspections due to time shortage for conducting reviews before product delivery. It is also demanded by them for code reviews whenever a project is in trouble. Until now, there has been no set methodology for doing project reviews, no requirement that reviews be conducted under defined circumstances or at specified points, and no precise qualifications required for project reviewers. Having this methodology, phase gate reviews, shown in figure 5 and a pool of reviewers shown in figure 4 (box darkened) provide added value to projects planned or under way. This also helps projects conduct reviews quickly on any aspect of their project provide reducing the iterations of project management reviews during project life cycles.

SQA provides the objective evidence that all life cycle processes have been properly and adequately performed. The IV \&V team conducts the phase gate reviews, provides the objective evidence of product compliance with the system's functional requirements and the users' needs. IV\&V is conducted parallel to, but separate from, the system software development activities. IV\&V apart from doing assessment activities like reviewing, analyzing, testing, and monitoring should act as technical advisors to help a project manager oversee a project by handling the project's schedule, budget, deliveries, etc. IV\&V group is composed of experienced domain experts, in-depth technical expertise with strong communication, management and planning skills for assessment, analysis, evaluation, review, inspection, and testing of software products and processes. In other words IV\&V 
maintains an overall system perspective and analyzes each activity to ensure that progress continues toward the completion of the system. This analysis includes ensuring that the configuration baseline is established and maintained and this approach will help to maintain system integrity. Both SQA and IV\&V will utilize the services of the expert pool, and PCM and TCM teams. It will help projects implement the best practices for ensuring the success of their projects and avoid failure of the projects. This ensures continuous improvement based on the industry's best practices and lessons learned from the reviews performed.

It is suggested that the organization has to focus on:

- Developing a set of criteria for the use of independent project reviews (IVV) - critical assessments of a project conducted by people who are at arm's length from it.
- Selecting independent reviewers from the established pools of qualified reviewers and these experienced reviewers are independent of the oversight functions in project. Phase Gate Review Program.

- The complexity monitoring during the phases of SDLC as shown in figure 5 to achieve a better control and a more robust estimate of the next phase, thus minimizing the project overruns.

- Using Software Reliability Growth Models by designers/developers to estimate the remaining bugs in the system which can be used to take a call on fit to release the product at phase gate 5 as the amount of testing needed to find and eliminate all the bugs is time and cost prohibitive.
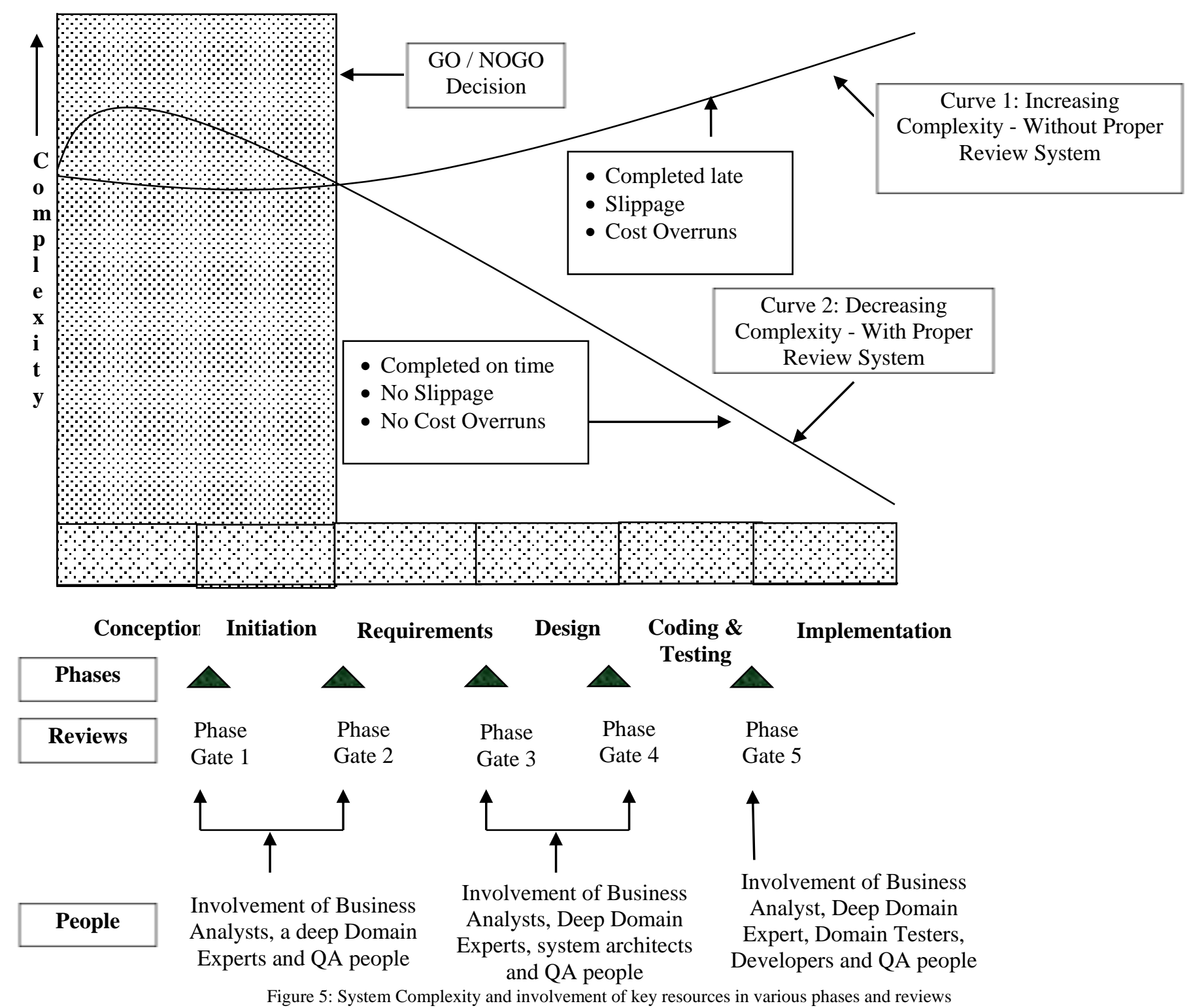

Figure 5: System Complexity and involvement of key resources in various phases and reviews 


\section{CONCLUSION}

In this paper we have proposed a theoretical model CQMS that stresses on establishing an expert pool to address the risk of failure due to an incorrect understanding of the project's goals. More and more organizations have to realize that they must be able to wire solutions together more quickly to get to market rapidly and be competitive. In a custom development projects, the needs of the customer are relatively static whereas, in a product development situation, the needs of the "marketplace" are constantly changing. To ensure this, the industry must adopt better practices for software development. For this the organizations need better governance and focus more on to standardizing a framework comprising process, tools, and assets that would help them save time and reduce project failures.

By making people aware of the above discussed practices / methods may significantly increase the effectiveness of the implementing process in the project life cycle. The future investigations need to happen in the direction that the existing methodologies (waterfall, spiral, agile etc.) may be critically examined by implementing the proposed framework to suggest improvements to the direction of implementing operational excellence through effective people practices.

\section{REFERENCES}

[1] Vanaja Arvind, Executive Director, Thinksoft Global Services Ltd, Chennai, http://bit.ly/F4TThinksoft, Business Line http://www.thehindu.com/business/Industry/article507513.ece

[2] Michael Krigsman, http://www.zdnetasia.com/study-68-percent-of-itprojects-fail-62049950.htm

[3] http ://www.irm.com.au /papers /what_is_a_business_analyst.pdf

[4] Who Killed the Virtual Case File?, http://www.spectrum.ieee.org/sep05/1455

[5] http://www.newswise.com/articles/view/513919?print-article, $10 / 14 / 2009$

[6] http://www.irm.com.au/papers/Golden _Rules_for_Business_analysts.pdf

[7] Sudha Gopalakrishnan, Vice President and Head-Business Process Excellence Group, Corporate Quality, Polaris Software Labs Ltd, Chennai, "Key Best Practices@ Polaris Software driving Operational Excellence, CSI Communications, Jan-2010, pp12-14

[8] Sankaran Venkatramani, Associate Director, KPMG, Chennai, "Operational Excellence through effective People Practices", CSI Communications, Jan-2010, pp 20-21.

[9] Derrick Brown, Jan Kusaik, IRM Training Pty Ltd, CSI Communications, May-2010, pp 7-10

[10] Patrick Malone, http://www.tagonline.org/articles.php?id=259, Project Failure, Jun 9, 2008.

[11] http://nclarity.net/data/Documentation/pmo.pdf

[12] Labuschagne C, Brent A.C, "Sustainable Project Life Cycle Management: Aligning Project Management Methodologies With The Principles Of Sustainable Development"

[13] Dave Breda, "Getting Far Beyond Stages and Gates", Pittiglio, Rabin, Todd \& Mcgrath, Inc., 2006

[14] http://www.iag.biz

\section{AUTHORS PROFILE}

Mr. A.Pathanjali Sastri is currently pursuing Ph.D Computer Science from Raylaseema University, Kurnool. He is woking as a Lecturer in Velagapudi Siddhartha Engineering college since 2008 and has 10 years of Industrial experience prior to this. $\mathrm{He}$ has published papers in reputed international conferences recently. He has 12 years of industrial experience and 2 years of teaching experience. His area of interest includes Software Engineering, Quality Assurance, Artificial Intelligence and RDBMS.

Dr. K. Nageswara Rao is currently working as Professor \& Head in the Department of Computer Science Engineering, Prasad V. Potluri Siddhartha Institute of Technology, Kanuru, Vijayawada-7. He has an excellent academic and research experience. He has contributed various research papers in the journals, conferences of International/national repute. His area of interest includes Artificial Intelligence, Software Engineering, Robotics, \& Datamining. 